\title{
Studi meta analisis: Efektivitas terapi menulis dalam menurunkan kecemasan orang dewasa dengan pengalaman traumatis
}

\author{
Putu Nitya Sarahdevina ${ }^{1}$, dan Ananta Yudiarso ${ }^{2}$
}

\begin{abstract}
Anxiety is often experienced by adults who have a less pleasant life experience. Writing therapy is an intervention that adults can use to express anxiety. This study aims to find out the effectiveness of writing therapy in lowering anxiety levels. The study used a meta-analysis method through a literature review of 14 research articles corresponding to research variables. The total number of participants in the study was 1,593. Data is analyzed by adjusting the effect size. The analysis results in effect size value obtained from fixed effects are $-0.06(95 \% \mathrm{Cl}=-0.167$ to $0.042, \mathrm{P}=$ 0.2434 ) and $I^{2}$ (inconsistency) by $66.9 \%$, which means that writing therapy has little effect in lowering anxiety levels. Writing therapy has little effect on decreasing anxiety levels. Writing therapy can be given in conjunction with other interventions in order to provide more optimal effects.
\end{abstract}

\section{Keywords}

Anxiety, adult, writing therapy, effect size

\section{Pendahuluan}

Data yang diperoleh dari Anxiety and Depression Association of America (ADAA) menunjukkan bahwa kecemasan merupakan penyakit mental yang paling umum di Amerika Serikat, menyerang 40 juta orang dewasa yang berusia 18 tahun ke atas, atau $18,1 \%$ dari populasi setiap tahunnya. Gangguan kecemasan dapat diobati, namun hanya $36,9 \%$ dari mereka yang menderita menerima perawatan. Selain itu, menurut World Health Organization (WHO), mengungkapkan bahwa 1 dari 13 individu secara global menderita kecemasan. WHO melaporkan bahwa gangguan kecemasan adalah gangguan mental yang paling umum terjadi di seluruh dunia (Anxiety and Depression Association of America , ADAA). Selain itu, berdasarkan data pada Kementerian Kesehatan tahun 2016, diketahui bahwa prevalensi gangguan mental emosional yang ditunjukkan dengan gejala-gejala depresi dan kecemasan untuk usia 15 tahun ke atas mencapai sekitar 14 juta orang atau $6 \%$ dari jumlah penduduk Indonesia.

Kecemasan yang dialami orang dewasa yang memiliki pengalaman traumatis merupakan reaksi emosi negatif yang diikuti dengan ketegangan somatis, seperti jantung berdetak kencang, berkeringat dan kesulitan bernafas. Penyebabnya karena penilaian terhadap kekhawatiran yang belum terjadi di masa depan. Kecemasan dapat dipengaruhi oleh beberapa faktor diantaranya adalah pengalaman negatif pada masa lalu, pikiran yang tidak rasional, perfeksionisme yang tinggi, generalisasi yang tidak tepat, adanya asumsi yang diyakini secara pribadi (Nevid et al., 2005) Gejala kecemasan dan depresi seringkali tidak dapat dipisahkan dan menyebabkan perilaku maladaptif (Mohammadian et al., 2011).

Kecemasan yang dirasakan individu tidak selalu berdampak negatif, munculnya perasaan cemas juga seringkali menimbulkan gagasan-gagasan kreatif dan mampu memotivasi individu menjadi lebih produktif. Cemas merupakan reaksi yang wajar dimiliki seseorang (Corey, 1996). Kecemasan juga berguna dalam memotivasi dan mendorong seseorang dalam melakukan suatu aktifitas misalnya belajar menjelang ujian. Kecemasan akan menjadi tepat ketika individu mampu dalam merespon secara tepat berdasarkan ancaman yang dihadapi, akan menjadi abnormal ketika tingkatannya tidak sesuai dengan proporsi ancaman atau bahkan tanpa ada penyebab yang mengikuti terjadi (Nevid et al., 2005).

Berdasarkan penelusuran penulis diketahui bahwa kecemasan orang dewasa dapat ditangani dengan mindfulness based stress reduction(Munazilah \& Hasanat, 2018); terapi bacaan Al-qur'an (Idham \& Ridha, 2017); relaksasi (Hayat, 2014); dan terapi menulis (Susilowati \& Hasanat, 2011). Pada penelitian ini, penulis fokus untuk mengkaji mengenai terapi menulis terhadap kecemasan

\footnotetext{
1,2 Universitas Surabaya
}

Korespondensi:

Sarahdevina, Fakultas Psikologi, Universitas Surabaya, Indonesia Email: s154119008@student.ubaya.ac.id 
orang dewasa. Beragam literatur sebelumnya telah mendukung efektivitas terapi menulis dengan metode kuantitatif eksperimen sehingga dirasa perlu untuk membuktikan konsistensinya. Adapun konsistensi efektivitas dari terapi menulis didalam menurunkan kecemasan dapat dilihat dari telaah literatur dengan pendekatan meta analisis.

Kecemasan yang dialami orang dewasa akibat adanya pengalaman traumatis dapat diatasi dengan menggunakan berbagai cara, salah satunya dengan mengekspresikan emosinya melalui tulisan atau dengan terapi menulis. Terapi menulis merupakan bentuk intervensi dengan meminta individu yang mengalami kecemasan untuk mengekspresikan pikiran dan perasaannya dalam bentuk tulisan. Individu diminta menuliskan pengalaman-pengalaman emosional maupun pengalaman traumatis yang dialami di masa lalu (Susilowati \& Hasanat, 2011). Menulis peristiwaperistiwa yang berkesan atau traumatis berpengaruh terhadap peningkatan sistem imun, kesehatan mental, mengurangi keluhan-keluhan fisik dan strategi yang dapat dilakukan untuk menyesuaikan diri atau koping terhadap stres atau kecemasan yang dimiliki (Pennebaker, 1997).

Penggunaan terapi menulis dapat dilakukan oleh berbagai pihak dari anak-anak hingga orang dewasa dan lanjut usia dengan berbagai latar belakang pendidikan maupun individu dengan kasus kriminal. Kasus-kasus yang seringkali menjadi cerita dalam penulisan adalah kasus percintaan, kematian, pelecehan seksual dan kekerasan. Individu seringkali merasa sedih dan menangis ketika diminta untuk menuliskan pengalaman traumatis yang dimiliki, namun sebagian besar juga mengungkapkan bahwa pengalaman menulis bermakna dan berharga bagi kehidupan mereka (Pennebaker \& Chung, 2011).

Berdasarkan paparan di atas dapat diketahui bahwa kecemasan membawa dampak buruk bagi individu dalam melakukan aktivitas sehari-hari. Salah satu intervensi yang dapat diberikan untuk menurunkan tingkat kecemasan pada orang dewasa yang memiliki pengalaman traumatis yaitu dengan memberikan intervensi terapi menulis. Oleh karena itu, penelitian ini bertujuan untuk mengetahui efektivitas terapi menulis dalam menurunkan kecemasan orang dengan pengalaman traumatis.

\section{Metode}

Penelitian ini menggunakan metode meta analisis yaitu penggunaan teknik statistika yang menggabungkan dua atau lebih penelitian sehingga diperoleh kelompok data secara kuantitatif yang sejenis. Meta analisis adalah suatu analisis integratif sekunder dengan menerapkan analisis berulang terhadap data untuk menjawab pertanyaanpertanyaan baru dengan data-data lama yang telah dimiliki. Dalam penelitian ini, penulis melakukan perhitungan terhadap effect size yang selanjutnya menjadi kesimpulan dari hasil penelitian yang dilakukan (Anwar, 2005).

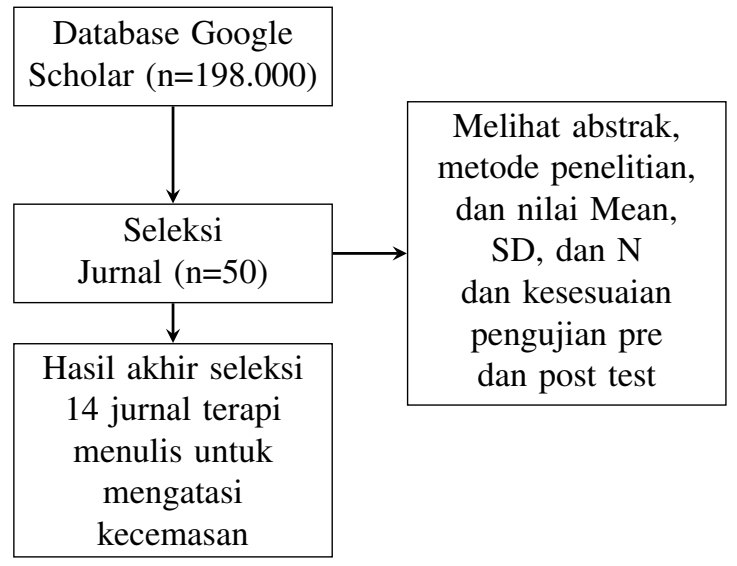

Gambar 1. Pencarian literatur

\section{Prosedur Statistik}

Penelitian ini bertujuan melihat hasil penerapan terapi menulis terhadap penurunan tingkat kecemasan melalui hasil post-treatment pada kelompok eksperimen dan kelompok kontrol. Penulis menghitung effect size dengan menggunakan stat direct trial version dengan melihat nilai Mean (M), Standart Deviation (SD) dan jumlah sampel (N) pada post-treatment. Uji analisis statistik dilakukan dengan menggunakan cohen d effect size dengan ukuran small effect size $(\mathrm{d} \leqslant 0,2)$, medium effect size $(\mathrm{d} \geqslant 0,2$ s.d $\leqslant 0,8)$, large effect size $(\mathrm{d} \geqslant 0,8)$ Peneliti juga melihat adanya bias publikasi dengan memperhatikan nilai eigger bias yang bergerak dari 0 hingga 1. Nilai Eigger bias yang tidak signifikan menunjukkan tidak adanya bias publikasi $(\mathrm{p}<0,05)$ (StatsDirect, 2020).

\section{Sumber Informasi dan Pencarian Literatur}

Sumber database yang digunakan untuk menelusuri dan mencari penelitian-penelitian terdahulu adalah Google Scholar. Kata kunci yang digunakan adalah (1)Expressive writing intervention (2) Anxiety theraphy (3) Expressive writing intervention for anxiety disorder. Pencarian jurnal dengan menggunakan Bahasa Inggris dan pemilihan jurnal terbatas pada jurnal internasional yang telah dipublikasikan dan menjalani proses review sebelumnya. Penelitian ini menggunakan data-data jurnal dengan limitasi tahun 2008-2019. Hasil dari pemilihan berjumlah 14 jurnal utama yang akan diolah. Proses pencarian jurnal pada penelitian ini tercantum pada gambar 1 .

\section{Hasil}

Karakteristik yang digunakan dalam penelitian ini dijelaskan pada Tabel 1. Jumlah partisipan keseluruhan yang digunakan adalah 1593 partisipan, terdiri dari kriteria yang berbeda-beda seperti pada Tabel 1 . 
Tabel 1. Hasil Penelitian Meta Analisis

\begin{tabular}{|c|c|c|c|c|c|c|c|c|c|}
\hline \multirow[b]{2}{*}{ Peneliti } & \multirow[b]{2}{*}{ Negara } & \multicolumn{2}{|c|}{ Partisipan } & \multirow[b]{2}{*}{ Skala } & \multirow[b]{2}{*}{$\mathrm{N}(\mathrm{KE})$} & \multirow[b]{2}{*}{$\mathrm{N}(\mathrm{KK})$} & \multirow[b]{2}{*}{ D } & \multirow[b]{2}{*}{$\mathrm{Cl}$} & \multirow[b]{2}{*}{ Metode } \\
\hline & & Usia & Jumah & & & & & & \\
\hline $\begin{array}{l}\text { Guastella \& Dadds } \\
(2008)\end{array}$ & Australia & 24 & $\begin{array}{l}198 \\
\text { Mahasiswa }\end{array}$ & DASS-21 & 157 & 41 & 0,423 & $0.08-0.77$ & $\begin{array}{l}\text { Menuliskan tentang hal-hal yang menjengkelkan } \\
\text { selama } 3 \text { minggu }\end{array}$ \\
\hline Dean et al. (2016) & London, UK & ¿18 & $\begin{array}{l}204 \\
\text { perempuan } \\
\text { UK, US }\end{array}$ & GAD-7 & 101 & 103 & -0.055 & $-0.33-0.22$ & $\begin{array}{l}\text { Menulis mengenai pengalaman stress/trauma } \\
\text { selama selama } 6 \text { bulan dan diupload di website }\end{array}$ \\
\hline Niles et al. (2014) & USA & $18-40$ & $\begin{array}{l}116 \text { subjek di } \\
\text { UCLA }\end{array}$ & DASS-7 & 59 & 57 & 0.037 & $-0.33-0.4$ & $\begin{array}{l}\text { Menulis mengenai pengalaman stress/trauma yang } \\
\text { dialami selama } 8 \text { minggu }\end{array}$ \\
\hline Coates et al. (2010) & Australia & $18-85$ & 129 dewasa & DASS-21 & 65 & 64 & -0.466 & $-0.82--0.12$ & $\begin{array}{l}\text { Menuliskan cara penyelesaian masalah dalam } \\
\text { menyelesaikan pengalaman stress/trauma selama } 3 \\
\text { minggu }\end{array}$ \\
\hline Kelly et al. (2012) & UK & 18 & 40 mahasiswa & DASS-21 & 20 & 20 & -0.284 & $-0.91-0.34$ & $\begin{array}{l}\text { Menuliskan tentang ketidak bahagiaan yang akan } \\
\text { diterima ketika mencapai tujuan hidup selama } 20 \\
\text { menit }\end{array}$ \\
\hline Ali et al. (2017) & Tokyo & $19-60$ & $\begin{array}{l}165 \text { pengguna } \\
\text { narkoba di RS } \\
\text { Pemerintahan } \\
\text { di Egypth }\end{array}$ & DASS-21 & 87 & 78 & -0.403 & $-0.71--0.09$ & $\begin{array}{l}\text { Menulis mengenai pengalaman stress/trauma } \\
\text { selama } 5 \text { hari di combine dengan CBT psycho } \\
\text { education }\end{array}$ \\
\hline $\begin{array}{l}\text { Mohammadian et al. } \\
\text { (2011) }\end{array}$ & Iran & $18-22$ & $\begin{array}{l}29 \\
\text { perempuan, } \\
\text { single }\end{array}$ & DASS-21 & 14 & 14 & -1.100 & $-1.9--0.31$ & $\begin{array}{l}\text { Menggunakan puisi Persian, dan menuliskan kalimat } \\
\text { kosong di puisi selama } 7 \text { minggu }\end{array}$ \\
\hline Baikie at al. (2012) & Australia & $18-65$ & $\begin{array}{l}225 \text { dari web- } \\
\text { site gangguan } \\
\text { mental }\end{array}$ & DASS & 139 & 86 & -0.211 & $-0.48-0.06$ & $\begin{array}{l}\text { Menulis mengenai pengalaman stress/trauma } \\
\text { selama } 2 \text { minggu }\end{array}$ \\
\hline Marx \& Dobbs (2008) & Boston & 18 & $\begin{array}{l}69 \text { mahasiswa } \\
\text { semester } 1\end{array}$ & DASS-21 & 35 & 34 & 0.14 & $-0.33-0.61$ & $\begin{array}{l}\text { Menulis mengenai pengalaman stress/trauma } \\
\text { selama } 20 \text { menit yang dilakukan selama } 3 \text { hari } \\
\text { berturut-turut }\end{array}$ \\
\hline Sloana et al. (2009) & Boston & 18 & $\begin{array}{l}68 \text { mahasiswa } \\
\text { semester } 1 \mathrm{di} \\
\text { USA }\end{array}$ & DASS-21 & 35 & 33 & 0.157 & $-0.32-0.63$ & $\begin{array}{l}\text { Menulis mengenai pengalaman stress/trauma } \\
\text { selama } 5 \text { minggu }\end{array}$ \\
\hline Amiri et al. (2019) & Iran & 57 & $\begin{array}{l}100 \text { pasien } \\
\text { pasca operasi } \\
\text { jantung di RS } \\
\text { Kordkus }\end{array}$ & DASS-21 & 50 & 50 & 0.525 & $0.13-0.92$ & $\begin{array}{l}\text { Menulis mengenai emosi negatif dan ingatan } \\
\text { tidak menyenangkan mengenai lamanya proses } \\
\text { administrasi, keadaan dirumah ataupun di rumah } \\
\text { sakit. selama } 7 \text { hari berturut-turut }\end{array}$ \\
\hline Koopman at al. (2018) & USA & $>18$ & $\begin{array}{l}49 \text { perempuan } \\
\text { di San Fran- } \\
\text { sisco }\end{array}$ & BDS & 25 & 22 & -0.161 & $-0.74-0.41$ & $\begin{array}{l}\text { Menulis mengenai pengalaman stress/trauma } \\
\text { selama } 20 \text { menit yang dilakukan selama sebulan }\end{array}$ \\
\hline $\begin{array}{l}\text { Relojo-Howella } \\
\text { Stoyanova(2019) }\end{array}$ & Bulgaria & $19-55$ & $\begin{array}{l}151 \\
\text { mahasiswa }\end{array}$ & WTAS & 101 & 50 & 0.055 & $-0.28-0.39$ & $\begin{array}{l}\text { Menulis mengenai pengalaman stress menghadapi } \\
\text { test atau tujuan yang hidup yang dimiliki selama } 3 \\
\text { hari }\end{array}$ \\
\hline
\end{tabular}


Dari 14 artikel penelitian pada tabel 1, perhitungan statistik dilakukan melalui analisis effect size dari kelompok eksperimen dan kelompok kontrol menunjukkan efektivitas writing therapy dalam menurunkan tingkat kecemasan. Berdasarkan nilai effect size yang diperoleh dari fixed effect adalah $-0,06(95 \% \mathrm{Cl}=-0,167$ sampai $0,042, \mathrm{P}=0,2434$ ) dan $I^{2}$ (inconsistency) sebesar 66,9\% $(95 \% \mathrm{CI}=31,5 \%$ to $80,1 \%)$. Nilai Eigger: bias $=0,500553$ (95\% CI $=-4,4512032$ to 3,510927 ). Hal ini menunjukkan bahwa intervensi writing therapy pada orang dewasa dengan pengalaman traumatis memiliki efek yang kecil dan tidak signifikan dalam menurunkan tingkat kecemasan.

\section{Diskusi}

Berdasarkan hasil meta analisis diketahui bahwa penggunaan intervensi terapi menulis memiliki efek yang kecil dalam menurunkan tingkat kecemasan orang dewasa yang memiliki pengalaman traumatis. Dari tersebut menunjukkan bahwa terapi menulis hanya memberikan efek terapeutik jangka pendek dalam mengatasi kecemasan. Oleh karena itu, dalam penerapannya, terapi menulis perlu disertai dengan pemberian intervensi lainnya sehingga dapat menurunkan tingkat kecemasan secara optimal. Hasil penelitian ini didukung oleh Pennebaker \& Chung (2011) bahwa terapi menulis dapat menjadi sarana katarsis bagi orang dewasa yang memiliki pengalaman traumatis. Orang dewasa yang mengikuti kegiatan terapi menulis, mendapatkan manfaat dengan menurunnya tingkat kecemasan yang dimiliki. Namun dengan sekadar mengikuti terapi menulis, tidak serta merta menghilangkan pengalaman masa lalu yang tidak menyenangkan sehingga perlu disertai dengan pemberian intervensi lainnya agar individu benar-benar dapat mengatasi kecemasannya.

Terapi menulis merupakan intervensi yang berfokus pada proses mengekspresikan emosi negatif yang dimiliki oleh individu. Terapi menulis mampu membantu proses terapeutik dalam proses penerimaan yang ambivalensi. Selain itu, teknik ini juga membantu agar individu dapat memikirkan lebih dalam tentang permasalahan internal yang dihadapi dan mampu memberikan dukungan untuk penguatan dalam peningkatan pemecahan masalah yang dihadapi (Kelly et al., 2012).

Dari hasil meta analisis, penerapan intervensi terapi menulis saja dianggap belum cukup efektif dalam mengatasi kecemasan yang dihadapi oleh individu. Hal ini disebabkan karena hasil dari meta analisis yang kecil dan tidak signifikan terhadap individu dengan gangguan kecemasan. Individu yang hanya menuliskan kecemasan yang dihadapi akan berfokus pada pengalaman negatif yang dihadapi sehingga tidak dapat mencapai tujuan hidup yang diharapkan (Relojo-Howella \& Stoyanova, 2019).

Terapi menulis juga tidak sepenuhnya memberikan efek positif terhadap gejala kecemasan yang dialami individu yang memiliki kesulitan dalam mengekspresikan emosinya. Individu yang kesulitan dalam mengekspresikan emosinya akan menilai penulisan yang dilakukannya secara berlebihan sehingga menjadikan pengungkapan melalui terapi menulis menjadikan kecemasan yang dimiliki justru meningkat. Pada individu yang mampu menyalurkan emosi dengan baik, terapi menulis juga tidak memberikan dampak yang signifikan. Hal ini dapat diakibatkan karena situasi stres tertentu yang lebih berpengaruh dibandingkan dengan kecemasan yang dialami (Niles et al., 2014).

Kurangnya efektivitas dari terapi menulis dapat disebabkan karena berbagai faktor, mulai dari perbedaan tingkat dan jenis kecemasan yang dialami individu dewasa. Dalam memberikan terapi menulis, akan lebih baik jika digabungkan dengan metode atau terapi lainnya contohnya dengan menggabungkannya dengan cognitive behavior therapy (Ali et al., 2017). Rendahnya efek dari writing therapy menjadi catatan penting bahwa dibutuhkan adanya dukungan terapi lain dalam menurunkan tingkat kecemasan pada orang dewasa yang memiliki pengalaman traumatis sehingga diharapkan menjadi jalan bagi individu untuk meningkatkan kesejahteraan psikologisnya. Terapi menulis membutuhkan waktu yang cukup lama dan memerlukan adanya penanganan ahli selama prosesnya. Selain itu, subjektifitas dari para ahli pada terapi menulis yang dilakukan juga seringkali membuat penggunaan terapi ini kurang efektif. Dalam penerapannya terapi menulis belum bisa memprediksi kapan penggunaan terapi ini harus digunakan dan untuk siapa sebaiknya penggunaan terapi ini diberikan sehingga dapat memberikan efek terapeutik yang maksimal (Pennebaker \& Chung, 2011).

Adapun keterbatasan pada studi ini small sample size yang diperoleh tidak dapat dijadikan dasar generalisasi terhadap semua partisipan karena nilainya yang kecil dan adanya batasan penggunaan dari metode, alat ukur, budaya dan jenis kecemasan yang terjadi. Hal ini menyebabkan tidak diketahui secara pasti penyebab kurangnya efektivitas dalam penggunaan terapi menulis. Sementara itu, implikasi dari penelitian ini yaitu untuk memaksimalkan efektivitas dari penerapan terapi menulis, maka perlu disertai dan dikombinasikan dengan intervensi lainnya.

\section{Kesimpulan}

Berdasarkan studi meta analisis yang telah dilakukan dapat disimpulkan bahwa writing therapy memiliki efektivitas yang rendah dalam menurunkan tingkat kecemasan orang dewasa dengan pengalaman traumatis. Terapi menulis dapat menjadi sarana katarsis bagi orang dewasa yang memiliki pengalaman masa lalu yang tidak menyenangkan. Namun demikian perlu adanya variasi teknik terapi pembanding atau penyerta untuk memaksimal penanganan pada pasien kesecemasan. Tentunya teknik terapi pembanding atau penyerta merupakan teknik yang trlah teruji secara klinis dan teruji konstensinya berdasarkan temuan atau riset terdahulu (evidence best practice). 


\section{Referensi}

Anxiety and Depression Association of America (ADAA). (2018). Facts and statistics. https://adaa.org/about-adaa/ press-room/facts-statistics.

Ali, A. M., Sharaf, A., Abdeldayem, S., \& Kawakami, N. (2017). The effect of expressive disclosure writing on self-stigma, depression, and anxiety among drug users in governmental hospital in egypt: A non-randomized controlled trial. Journal of Depression and Anxoety Disorder, 1(1), 31-40. https://doi. org/10.36959/362/471

Amiri, Z. B., Sanagoo, A., Jouybari, L., Bahnampour, N., \& Kavosi, A. (2019, April). The effect of written emotional disclosure on depression, anxiety, and stress. Broad Research in Artificial Intelligence and Neuroscience, 10(2), 55-64.

Anwar, R. (2005). Meta analisis. Pustaka Unpad, 1-20. http://pustaka.unpad.ac.id/wp-content/uploads/2010/05/ meta_analisis.pdf

Baikie, K.A., Wilhelm, K., Johnson, B. et al. (2006) Expressive writing for high-risk drug dependent patients in a primary care clinic: A pilot study. Harm Reduct J 3, 34. https://doi. org/10.1186/1477-7517-3-34

Baikie, K. A., Geerligs, L., \& Wilhelm, K. (2012). Expressive writing and positive writing for participants with mood disorders: An online randomized controlled trial. Journal of Affective Disorders, 310-319. https://doi.org/10.1016/j.jad. 2011.11.032

Coates, C., Malouff, J. M., \& Rocke, S. E. (2010). Efficacy of written modeling and vicarious reinforcement in increasing use of problem-solving methods by distressed individuals. The Journal of Psychology: Interdisciplinary and Applied,142(4), 413-425. https://doi.org/10.3200/JRPL. 142.4.413-426

Corey, G. (1996). Theory and practice of counseling and psychotherapy Edisi ke-5. Monterey, California: Brooks/Cole Publishing Company.

Guastella, A. J., \& Dadds, M. R. (2008). Cognitive-behavioural emotion writing tasks: A controlled trial of multiple processes. Journal of Behavior Therapy and Experimental Psychiatry, 39(4), 558-566. https://doi.org/10.1016/j.jbtep. 2007.11.008

Dean, P. J., Potts, P. H. W. W., \& Barker, P. C. (2016). Direction to an internet support group compared with online expressive writing for people with depression and anxiety: a randomized trial. JMIR Mental Health, 3(2), 1-16. https://doi.org/10. 2196/mental.5133

Hayat, A. (2014). Kecemasan dan metode pengendaliannya. Khazanah: Jurnal Studi Islam dan Humaniora, XII(1), 5262. http://dx.doi.org/10.18592/khazanah.v12i1.301

Idham, A. F., \& Ridha, A. A. (2017). Apakah mendengarkan murottal al-quran dapat menurunkan kecemasan akademik pada mahasiswa? Jurnal Intervensi Psikologi, 9(2), 1-14. https://doi.org/10.20885/intervensipsikologi.vol9.iss2.art1

Kelly,R.E, Wood, A.M., Shearman, K., Phillips. S., \& Mansell. W. (2012).Encouraging acceptance of ambivalence using the expressive writing paradigm. Psychology and psychotherapy, 85(2), 220-228. https://doi.org/10.1111/j.20448341.2011.02023.x

Kementerian Kesehatan (2016). Peran Keluarga Dukung Kesehatan Jiwa Masyarakat. (Online), https://www.kemkes. go.id/article/print/16100700005/peran-keluarga-dukungkesehatan-jiwa-masyarakat.html

Koopman, C., Ismailji, D. H. T., \& et. (Maret 2018). The effect of expressive writing on pain, depression and posttraumatic stress disorder symptoms in survivors of intimate partner violance. Journal of Health Psychology, 10(2), 211-221. https://doi.org/10.1177/1359105305049769

Mohammadian, M. Y., Shahidi, P. S., Mahaki, M. B., Mohammadi, P. A. Z., Baghban, P. A. A., \& Zayeri, P. F. (2011). Evaluating the use of poetry to reduce signs of depression, anxiety and stress in Iranian female student. The Arts in Psychotherapy, 38(1), 59-63. https://doi.org/10.1016/ j.aip.2010.12.002

Munazilah, \& Hasanat, N. U. (2018). Program mindfulness based stress reduction untuk menurunkan kecemasan pada individu dengan penyakit jantung koroner. Gadjah Mada Journal Of Professional Psychology (GAMAJPP), 4(1), 22-32. https:// doi.org/10.22146/gamajpp.45346

Nevid, J. S., Rathus, S. A., \& Greene, B. (2005). Psikologi Abnormal Edisi 5 Jilid 1. Jakarta: Erlangga.

Niles, A. N., Haltom, K. E., Mulvenna, C. M., \& Mulvennanna, C. M. (2014). Effects of expressive writing on psychological and physical health: The moderating role of emotional expressivity. Anxiety Stress Coping, 27(1), 1-19. https://doi. org/10.1080/10615806.2013.802308

Pennebaker, J. W. (1997). Writing about emotional experience as a therapeuitoc process. Psychological Science, 8(3), 162166. https://doi.org/10.1111/j.1467-9280.1997.tb00403.x

Pennebaker, J. W., \& Chung, C. K. (2011). Expressive writing: Connections to physical and mental health. In H. S. Friedman (Ed.), The Oxford handbook of health psychology (pp. 417-437). Oxford University Press. https://doi.org/10.1093/ oxfordhb/9780195342819.013.0018

Relojo-Howella, D., \& Stoyanova, S. (2019). Expressive writing as an anxiety-reduction intervention on test anxiety and the mediating role of first language and self critism in Bulgarian sample. Journal of Educational Sciences \& Psychology, 9(71), 121-130.

Sloan, D. M., Feinsteina, B. A., \& Marxa, B. P. (2009). The durability of beneficial health effects associated with expressive. Anxiety, Stress, \& Coping: An, 22(5), 509-523. https://doi.org/10.1037/1528-3542.8.2.302

Sloan D.M., Marx, B.P., Epstein, E.M., Dobbs, J.L. (2008).Expressive writing buffers against maladaptive rumination. Emotion. 8(2),302-6. https://doi.org/10.1037/ 1528-3542.8.2.302

StatsDirect. (2020). Statistical help. Retrieved Mei 14, 2020 from Stats Direct: https://www.statsdirect.com/help/Default.htm\# basics/p_values.htm 
Susilowati, T. G., \& Hasanat, N. U. (2011). Pengaruh terapi menulis pengalaman emosional terhadap penurunan depresi pada mahasiswa tahun pertama. Jurnal Psikologi, 38(1), 92107. https://doi.org/10.22146/jpsi.7669 